\title{
PENGATURAN JUMLAH CABANG UTAMA DAN PENJARANGAN BUAH TERHADAP MUTU BENIH TOMAT VARIETAS KALIURANG (Lycopersicum esculentum Mill )
}

\author{
SRI SUGIHARTININGSIH DAN AGUS WARTAPA
}

STPP Jurusan Penyuluhan dan Pertanian di Yogyakarta

\begin{abstract}
This research used factorial device $3 \mathrm{X} 3$ that compiled pursuant to Randomized Completely Block design consist of 2 factor and 3 restating. First factor was arrangement of amount main branch, consist of 3 level, that were: 1 main branch, 2 main branch, and 3 main branch. Second factor was fruit seldom, consist of without seldom, seldom $15 \%$ and seldom $30 \%$. Data was analysed by manner sidik, if there were significant continued with Duncan Multiple Range Test level 5\%.

Result of research indicated that arrangement amount of main branch 3 branch and fruit seldom equal to $15 \%$ or $30 \%$ have significant an effect to high crop, energy grow seed, heavy seed 1000 item.
\end{abstract}

Keyword: main branch, fruit seldom, quality of seed.

\section{PENDAHULUAN}

Tomat varietas kaliurang merupakan komoditas unggulan Propinsi Daerah Istimewa Yogyakarta. Potensi hasil tanaman tomat Kaliurang berkisar $40-50$ ton/ha; ini lebih tinggi dibanding varietas tomat lain seperti tomat varietas ratna (524 ton/ha) dan intan (5-20 ton/ha).

Dalam budidaya tanaman tomat varietas kaliurang pada umumnya tidak dilakukan penjarangan buah. Untuk memperoleh mutu buah tomat yang baik sebagai sumber benih dipilih buah tomat yang sesuai dengan diskripsi tomat varietas kaliurang. Suhu yang baik untuk pertumbuhan tanaman tomat adalah $21-24^{\circ} \mathrm{C}$ pada siang hari dan $15-20{ }^{\circ} \mathrm{C}$ pada malam hari, (Deanon, 1967). Tempertur pada siang hari lebih dari $38^{\circ} \mathrm{C}$ selama 1-3 hari setelah penyerbukan menyebabkan embrio mengalami kerusakan, sehingga biji yang terbentuk tidak baik (Alvin, at all, 1999).

Jumlah cabang pada tanaman tomat akan berpengaruh terhadap mutu buah maupun mutu benih. Cabang tanaman yang sedikit dimungkinkan mutu buah dan benih meningkat. Asimilat yang terbentuk sepenuhnya dapat disimpan pada buah maupun biji dan menyebabkan buah maupun biji menjadi lebih besar, sehingga mutu buah maupun benih meningkat. Sebaliknya apabila jumlah cabang pada tanaman tomat banyak, maka asimilat banyak dipergunakan untuk pertumbuhan tunas tunas baru, sehingga asimilat yang tersimpan pada buah maupun biji berkurang dan selanjutnya menyebabkan asimilat yang disimpan pada buah dan biji lebih sedikit. Oleh karena asimilat yang disimpan pada buah sedikit, dapat mengakibatkan mutu buah maupun benih menurun.
Mutu benih ditentukan oleh faktor genetik seperti produktifitas dan faktor fisik seperti tingkat kecacatan buah. Mutu benih meliputi beberapa komponen antar lain: kemurnian benih (high purity), daya tumbuh benih (high viability and vigor), kadar air (moisture content of seed) campuran benih lain. Persyaratan utama yang dimiliki pada benih adalah: daya tumbuh minimal $80 \%$, kemurnian benih minimal $95 \%$, benih campuran maksimal $2 \%$, kotoran benih maknimal $2 \%$ dan benih rumput maksimal $2 \%$. (Kamil, 1979). Benih vigor adalah benih yang mampu bertahan dan berkecambah serta menghasilkan benih yang tumbuh baik dilapangan yang beragam dan luas (Sadjad, 1980). Sementara menurut Mc Donal dan Copeland,(1985) mengatakan bahwa vigor benih sebagai keseluruhan sifat yang menggambarkan potensi dari aktifitas dan penampilan benih selama berkecambah. Benih bermutu tinggi adalah benih yang memiliki daya tumbuh diatas $90 \%$, viabel, murni dan sesuai dengan namanya (Jannick et all.(1969) cit. Sudikno,1977). Benih yang menunjukkan penampilan baik dinyatakan bervigor tinggi, sedangkan benih yang mempunyai penampilan kurang baik dikelompokkan kedalam benih bervigor rendah. Heydecker, (1972) berpendapat benih vigor dicirikan oleh beberapa karateristik , yaitu: berkecabah cepat dan merata, bebas dari penyakit, tahan terhadap gangguan mikroorganisme, tumbuh kuat dalam keadaan lapangan yang kurang menguntungkan, efisien dalam memanfaatkan cadangan makanan, tahan disimpan, laju pertambahan berat kering yang tinggi, menghasilkan tanaman yang berproduksi tinggi, tidak menunjukkan perbedaan pertumbuhan 
dilapangan dan dilaboratorium, dan tahan terhadap persiangan.

Benih bermutu merupakan salah satu masukan yang menentukan mutu dan jumlah hasil. Sarana produksi lain seperti pupuk, pestisida, zat pengatur tumbuh dan cara budidaya yang baik tidak akan memberikan hasil yang baik apabila mutu benih tidak baik. Yang dimaksud dengan benih bermutu ialah benih yang berkualitas tinggi bersal dari jenis unggul dan telah memenuhi persyaratan ditanam. Benih yang berkualitas tinggi memiliki daya tumbuh diatas $90 \%$, viabel, murni, dan sesuai dengan namanya.

\section{METODOLOGI PENELITIAN}

Penelitian dilaksanakan di Kebun Praktek Sekolah Tinggi Penyuluhan Pertanian Magelang Jurusan Penyuluhan Pertanian Jalan Kusumanegara No. 2 Yogyakarta mulai bulan Pebruari 2007 sampai bulan Juli 2007. Lokasi penelitian ini terletak kurang lebih $115 \mathrm{~m}$ di atas permukaan air laut, jenis tanahnya regosol, rerata suhu udara 26,54 ${ }^{\circ} \mathrm{C}$, curah hujan $2.158 \mathrm{~mm} / \mathrm{th}$.

Penelitian ini menggunakan rancangan percobaan faktorial $3 \times 3$ yang disusun berdasarkan
Rancangan Acak Kelompok Lengkap (RAKL) dengan 3 blok sebagai ulangan. Perlakuan terdiri dari dua faktor yaitu pemangkasan cabang utama dan penjarangan buah.. Cabang dipangkas sehingga tanaman mempunyai 1 cabang utama (C1), 2 cabang utama (C2), dan 3 cabang utama (C3). Panjarangan buah adalah tanpa penjarangan buah (B0), penjarangan buah $15 \%$ (B1), penjarangan buah $30 \%$ (B2).

Data dianalisis dengan metode sidik ragam, pada tahap awal digunakan Analisis Varian dengan taraf 5\%, kemudian dilanjutkan dengan menggunakan Analisis Uji Lanjut DMRT (Duncan Multiple Range Test) taraf 5\%.

\section{HASIL DAN PEMBAHASAN}

\section{Rerata rendemen biji}

Hasil analisis terhadap rendemen biji menunjukkan tidak adanya interaksi. Rendemen biji pada perlakuan jumlah cabang utama tidak menunjukkan berbeda nyata, pengaturan 1 cabang cenderung memberikan rendemen biji yang tinggi terhadap perlakuan lainnya. Perlakuan penjarangan buah $0 \%$ (B0) nyata lebih tinggi dibanding dengan yang lain.

Tabel 1. Rerata Rendemen Biji

\begin{tabular}{|c|c|c|c|c|}
\hline \multirow[b]{2}{*}{ Jumlah Cabang Utama } & \multicolumn{3}{|c|}{ Penjarangan buah } & \multirow[t]{2}{*}{ Rerata } \\
\hline & $0 \%$ & $15 \%$ & $30 \%$ & \\
\hline 1 cabang & 0,70 & 0,63 & 0,60 & $0,64 \mathrm{a}$ \\
\hline 2 cabang & 0,63 & 0,57 & 0,60 & $0,60 \mathrm{a}$ \\
\hline 3 cabang & 0,60 & 0,63 & 0,57 & $0,60 \mathrm{a}$ \\
\hline Rerata & $0,64 \mathrm{p}$ & $0,61 \mathrm{pq}$ & $0,59 \mathrm{q}$ & - \\
\hline
\end{tabular}

Sumber data : Analisis data primer

Keterangan

* Rerata dalam kolom atau baris yang diikuti oleh huruf yang sama tidak menunjukkan benda nyata pada jenjang $5 \%$ berdasarkan uji jarak berganda Duncan.

(-) Tidak ada interaksi

\section{Rerata Berat Biji 1000 Butir}

Hasil analisis terhadap variabel berat biji 1000 butir menunjuknan adanya interaksi. Rerata berat biji tertinggi diperoleh dari kombinasi perlakuan jumlah 1 cabang (C1) dengan penjarangan buah sebesar $30 \%$ ( B2), sedangkan terendah diperoleh pada jumlah 3 cabang dengan penjarangan buah sebesar $15 \%(\mathrm{C} 3 \mathrm{~B} 1), \mathrm{C} 3 \mathrm{~B} 2$.

Tabel 2. Rerata Berat Biji 1000 butir, dalam gram

\begin{tabular}{ccccc}
\hline & \multicolumn{3}{c}{ Penjarangan Buah } & \multirow{2}{*}{ Rerata } \\
\cline { 2 - 4 } Jumlah Cabang Utama & $0 \%$ & $15 \%$ & $30 \%$ & \\
\hline 1 cabang & $3,27 \mathrm{~b}$ & $3,28 \mathrm{~b}$ & $3,34 \mathrm{a}$ & 3,30 \\
2 cabang & $3,17 \mathrm{c}$ & $3,14 \mathrm{~d}$ & $3,15 \mathrm{~cd}$ & 3,15 \\
3 cabang & $3,11 \mathrm{e}$ & $3,09 \mathrm{e}$ & $3,09 \mathrm{e}$ & 3,10 \\
\hline Rerata & 3,18 & 3,17 & 3,19 & + \\
\hline
\end{tabular}

Sumber data : Analisis data primer

\section{Keterangan}

* Rerata dalam kolom atau baris yang diikuti oleh huruf yang sama tidak menunjukkan benda nyata pada jenjang $5 \%$ berdasarkan uji jarak berganda Duncan. 
(+) Ada interaksi

(-) Tidak ada interaksi

\section{Rerata Daya Tumbuh Biji}

Hasil analisis pada variabel daya tumbuh biji menunjukkan adanya interakasi. Daya tumbuh tertinggi diperoleh dari kombinasi antara perlakuan jumlah 1 cabang (C1) dengan penjarangan buah sebesar $30 \% \quad$ (B2), sedangkan terrendah adalah jumlah 2 cabang (C2) dengan penjarangan buah sebesar $0 \%$ (B0).

Tabel 3. Rerata Daya Tumbuh Biji, dalam \%

\begin{tabular}{|c|c|c|c|c|}
\hline \multirow[b]{2}{*}{ Jumlah Cabang Utama } & \multicolumn{3}{|c|}{ Penjarangan buah } & \multirow[t]{2}{*}{ Rerata } \\
\hline & $0 \%$ & $15 \%$ & $30 \%$ & \\
\hline 1 cabang & $97,67 \mathrm{ab}$ & $97,33 \mathrm{ab}$ & 98,33 a & 97,78 \\
\hline 2 cabang & $96,67 \mathrm{~b}$ & $98,00 \mathrm{ab}$ & $98,00 \mathrm{ab}$ & 97,56 \\
\hline 3 cabang & $97,33 \mathrm{ab}$ & $97,00 \mathrm{ab}$ & $96,67 \mathrm{~b}$ & 97,00 \\
\hline Rerata & & 97,44 & 97,67 & + \\
\hline
\end{tabular}

Sumber data : Analisis data primer

Keterangan

* Rerata dalam kolom atau baris yang diikuti oleh huruf yang sama tidak menunjukkan benda nyata pada jenjang $5 \%$ berdasarkan uji jarak berganda Duncan

(+) Ada interaksi

(-) Tidak ada interaksi

\section{Rerata Coefisien Vigor}

Hasil analisis pada variabel coefisien vigor menunjuknan adanya interaksi. Kombinasi perlakuan jumlah 1 cabang (C1) dengan penjarangan buah sebesar $\quad 0 \%(\mathrm{~B} 0)$ memberikan coefisien vigor paling tinggi, sedangkan terendah adalah jumlah 3 cabang (C3) dengan penjarangan buah sebesar $30 \%$ (B2) dan jumlah 1 cabang (C1) dengan penjarangan buah sebesar $30 \%$ (B2).

$\underline{\text { Tabel } 4 \text { Rerata Coefisien Vigor }}$

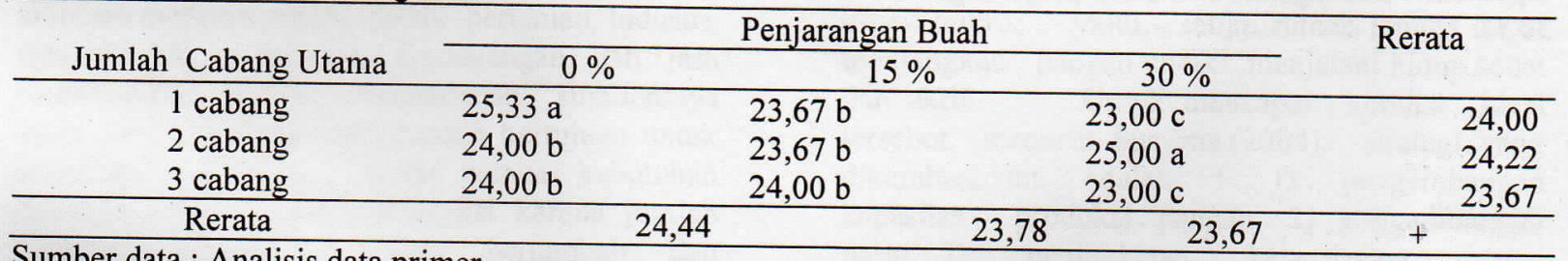

Sumber data : Analisis data primer

Keterangan

* Rerata dalam kolom atau baris yang diikuti oleh huruf yang sama tidak menunjukkan benda nyata pada jenjang $5 \%$ berdasarkan uji jarak berganda Duncan.

(+) Ada interaksi

(-) Tidak ada interaksi

Pengamatan terhadap mutu benih tidak ada interaksi antara perlakuan pengaturan jumlah cabang utama dengan penjarangan buah pada variabel rendemen benih. Namun perlakuan pengatuaran jumlah cabang utama 1 cabang relatif memberikan rendemen yang lebih tinggi. Kejadian ini dimungkinkan proses pengisian buah relatif lebih baik, sehinnga pembentukan biji lebih baik dari yang lain. Jumlah buah relatif dapat meningkatkan rendemen biji, karena volume buah lebih banyak berisi biji yang terbentuk.

Terhadap variabel berat 1000 butir biji terdapat interaksi terhadap kedua perlakuan, sehingga kombinasi perlakuan paling baik adalah salah satu pertimbangan dalam tujuan pencapaian berat 1000 butir. Dalam hal ini kombinasi jumlah cabang utama 1 cabang dengan penjarangan buah $30 \%$ memberikan berat 1000 butir tertinggi. Hal ini dimungkinkan jumlah cabang utama 1 cabang fotosintesis lebih optimal sehingga asimilat maksimal, sedangkan penjarangan buah $30 \%$ mengakibatkan pengisian lebih baik. Demikian pula daya tumbuh biji dengan kondisi seperti tersebut kombinasi perlakuan pengaturan jumlah cabang utama 1 cabang dan penjarangan buah $30 \%$ daya tumbuh biji paling tinggi dan paling baik. Dari kedua kombinasi perlakuan ini daya tumbuh biji 
tomat semuanya diatas patokan yang ditetapkan yaitu diatas $85 \%$.

Coefisien vigor adalah salah satu metode untuk mengekpresikan vigor bibit. Kecepatan berkecambah secara serempak merefleksikan jumlah benih yang berkecambah pada interval satu hari setelah dikecambahkan. Coefisien vigor yang tinggi mencerminkan cepat dan serempaknya bibit tumbuh di lapangan, yang berarti biji cepat menyesuaikan lingkungan dan tumbuh menjadi individu baru. Dalam hal ini kombinasi perlakuan pengaturan jumlah cabang utama 1 dengan tanpa penjarangan buah memberikan nilai coefisien vigor paling baik.

\section{KESIMPULAN DAN SARAN \\ Kesimpulan}

Berdasarkan hasil penelitian, analisis data dan pembahasan pada penelitian ini dapat diambil kesimpulan sebagai berikut: Kombinasi perlakuan pengaturan jumlah 1 cabang utama dan penjarangan buah $15 \%$, memberikan berat biji 1000 butir tertinggi.

\section{Saran}

Untuk memperoleh mutu benih (berat biji 1000 butir) terbaik sebaiknya tanaman tomat dipeihara 1 cabang dan dilakukan penjarangan buah $30 \%$.

\section{DAFTAR PUSTAKA}

Alvin, at all. 1999. Commercial Tomato Production. The University of Tennessec of Agriculture. 20 page.

Deanon,MD, 1967. Fruit and vegetables Perganon Press. London 306 page.*

Heydecker, W. 1972. Vigour in hibility of Seed. Chapman and Hall Ltd. London. 448 page.

Jurnalis Kamil, 1986. Teknologi Benih. Angkasa Raya Padang. 12-14 hal*.

Mc Donald, MB. And L.O. Copeland. 1985. Principles of seed Science and Tecnology. Macmillan Publish Co. 321 page.

Sadjad,S. 1980. Panduan pembibitan Mutu Benih Tanaman Kehutanan Indonesia. IPB Bogor. 130 hal.

Sudikno, Titi Sudarti. 1977. Teknologi Benih Yayasan Pembina FP. UGM. Yogyakarta. 101 hal 